Л.И.Двореикий

Интерстициальные заболевания легких у пожилых

ГБОУ ВПО "Первый Московский государственный медицинский университет им. И.М.Сеченова" Минздрава России: 119991, Москва, Трубеецкая, 8, стр. 2

\title{
L.I.Dvoretskiy \\ Interstitial lung disease in elderly
}

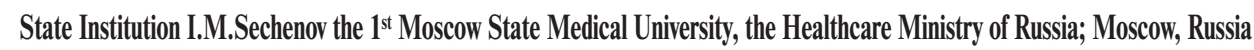

\section{Summary}

Interstitial lung disease in elderly are one of the most important issues of geriatric pneumology. Among them, idiopathic pulmonary fibrosis (IPF) is the most important clinical problem with increasing rate as ageing. In elderly, the rate of IPF is higher than in younger populations. Epidemiologic data are shown in the article and pathogenesis of the disease is discussed considering senile changes in the lungs, course and prognosis on a ground of age-related co-morbidity, diagnosis focused on the most reliable and safe methods and pathogenetic well-tolerated treatment approach.

Key words: elderly and senile age, interstitial lung disease, senile lung, idiopathic pulmonary fibrosis, co-morbidity.

\section{Резюме}

Интерстициальные заболевания легких у пожилых представляют одну из важных проблем геронтологической пульмонологии. Наибольшее клиническое значение имеет идиопатический легочный фиброз, частота которого возрастает по мере старения и у пожилых лиц превышает таковую в более молодых возрастных группах. Приводятся эпидемиологические данные, обсуждаются вопросы патогенеза заболевания с учетом его развития на фоне сенильного легкого, особенности течения и прогноза в условиях старческой полиморбидности, диагностики с акцентом на наиболее информативные и безопасные методы, а также различные способы лечения в расчете на их патогенетическое действие и переносимость.

Ключевые слова: пожилой и старческий возраст, интерстициальные заболевания легких, сенильное легкое, идиопатический легочный фиброз, коморбидность.

Среди легочной патологии у больных пожилого и старческого возраста, наряду с хорошо известными острыми и хроническими заболеваниями с характерными особенностями течения (пневмония, хроническая обструктивная болезнь легких - ХОБЛ, бронхиальная астма), наименее изученными являются интерстициальные заболевания легких (ИЗЛ). ИЗЛ - гетерогенная группа преимущественно хронических заболеваний легочной ткани, с общими клиническими проявлениями, изменениями физиологии дыхания и определенным патоморфологическим сходством. Принято различать ИЗЛ с известной и неизвестной этиологией. В основе ИЗЛ лежат воспаление и нарушение структуры респираторных отделов легкого (бронхиолы, альвеолы) и интерстиция (эндотелия легочных капилляров, перивазальных и перилимфатических тканей) с развитием в большинстве случаев пневмофиброза (фиброзирующие ИЗЛ), проявляющиеся признаками прогрессирующей легочной недостаточности [1]. К известным этиологическим факторам ИЗЛ относятся воздействие органических и неорганических веществ, лекарственные препараты, инфекции, системные заболевания. В большинстве случаев причины ИЗЛ остаются неясными, в связи с этим такие формы заболевания принято обозначать как идиопатические (идиопатические интерстициальные пневмонии, идиопатический фиброзирующий альвеолит).

Со времени первых сообщений об ИЗЛ, появившихся в конце XIX - начале XX вв., менялись представления о причинах, патогенезе, морфологических вариантах заболевания, что отражалось в различных классификациях ИЗЛ [2, 3]. Последний пересмотр классификации ИЗЛ, основанный на клинических особенностях заболевания, был предложен в 2012 г. В современных классификациях выделена большая группа идиопатических интерстициальных пневмоний (ИИП), включающая идиопатический легочный фиброз (ИЛФ), неспецифическую интерстициальную, криптогенную организующуюся, десквамативную интерстициальную, острую интерстициальную и лимфоидную интерстициальную пневмонии, а также респираторный бронхиолит с ИЗЛ [4, 5].

Наиболее часто встречающейся формой ИИП является ИЛФ (морфологический синоним - обычная интерстициальная пневмония), составляющий $\approx 60 \%$ всех наблюдений и встречающийся, как правило, у лиц пожилого и старческого возраста. В последней классификации ИЗЛ номинация ИЛФ пришла на смену ранее существовавшему термину "идиопатический фиброзирующий альвеолит". ИЛФ характеризуется прогрессирующим фиброзом, развивающимся преимущественно в периферических отделах легких и в нижних долях с формированием в конечной фазе развития "сотового" легкого [6]. Целью данной работы явилось рассмотрение главным образом гериатрических аспектов ИЛФ.

\section{Эпидемиология ИЗЛ в позднем возрасте}

У детей ИЗЛ возникают довольно редко, развиваясь главным образом у взрослых, частота их увеличивается с возрастом. Особенно это касается ИЛФ - заболевания, в некоторых исследованиях обозначаемых как 
болезнь пожилых и стариков [7]. На связь ИЛФ с возрастом указывалось еще в начале XX века [8], а позднее было установлено, что средний возраст пациентов с ИЛФ составляет $\approx 65$ лет, в то время как среди молодых лиц данное заболевание встречается чрезвычайно редко [9]. В юго-западных регионах США заболеваемость и распространенность ИЗЛ в год составляет 11 и 20 на 100 тыс. случаев среди мужчин и 7 и 13 на 100 тыс. - среди женщин соответственно [10]. В Великобритании заболеваемость ИЛФ составляет 4,6 на 100 тыс. человеко-лет, причем было отмечено прогрессивное увеличение заболеваемости за периоды с 1991-1995 до 2000-2003 гг. [11]. В одном из последних эпидемиологических анализов [9] с использованием относительно жестких диагностических критериев (диагностический код ИЛФ + процедурный код для легочной биопсии, трансбронхиальной биопсии или компьютерной томографии - КТ) заболеваемость и распространенность ИЗЛ составляли 6,8 и 14,0 случая на 100 тыс. в год. При использовании расширенных диагностических критериев (только диагностический код ИЛФ) заболеваемость и распространенность ИЗЛ достигали 16,3 и 42,7 случая на 100 тыс. в год соответственно. В исследованиях [9, 10] был отмечен впечатляющий рост заболеваемости и распространенности ИЛФ с возрастом. В одном из них [10] сообщалось, что заболеваемость и распространенность ИЛФ у лиц в возрасте 75 лет и старше достигали 102 и 175 случаев на 100 тыс. в год для мужчин и 57 и 73 случая на 100 тыс. в год для женщин соответственно. В другом исследовании [9] заболеваемость и распространенность среди мужчин составили 71 и 271 случай на 100 тыс. в год, а для женщин - 67 и 266 случаев на 100 тыс. в год соответственно. В недавно опубликованном исследовании [7] также были зарегистрированы высокие показатели заболеваемости и распространенности ИЛФ у лиц в возрасте 70-79 лет, которые приближалась к заболеваемости и распространенности рака легкого и колоректального рака у пожилых. В 1992-2003 гг. в США за 10-летний период возросла летальность от ИЛФ [12].

\section{Патогенетические особенности развития ИЛФ в пожилом и старческом возрасте}

Развитие, течение и терапия ИЗЛ у лиц пожилого и старческого возраста имеют следующие особенности:

- развитие заболевания на фоне происходящих эволютивных морфологических и функциональных изменений легочной ткани (сенильное легкоe);

- частое наличие у пожилых сопутствующей патологии (сердечно-сосудистые и системные заболевания, патология желудочно-кишечного тракта, злокачественные опухоли и т. п.), которые могут в ряде ситуаций приобретать патогенетическое значение в развитии ИЛФ;

- течение заболевания в сочетании с другой, накапливающейся с годами патологии (ишемичес- кая болезнь сердца - ИБС, артериальная гипертензия - АГ, сердечная недостаточность, ХОБЛ и т. п.), что усугубляет тяжесть основного заболевания (феномен взаимного отягощения) и трудности ведения пациентов;

- накапливающиеся за долгую жизнь экзогенные воздействия на бронхолегочную систему (курение, бытовые, профессиональные факторы и т. п.) могут становиться этиологически значимыми факторами развития ИЛФ в позднем возрасте;

- медикаментозный прессинг (полипрагмазия), испытываемый пожилыми пациентами по поводу характерной для данной возрастной группы полиморбидности.

Основными возрастными структурно-функциональными изменениями бронхолегочной системы, обозначаемыми термином "сенильное легкое", являются [13-15]:

- гиперинфляция с увеличением "мертвого" пространства;

- снижение показателей объема форсированного выдоха за 1-ю секунду и жизненной емкости легких;

- снижение силы дыхательной мускулатуры;

- повышение ригидности грудной стенки;

- увеличение остаточного объема легких;

- утрата эластической тяги легких;

- снижение вентиляционного ответа на изокапническую гипоксию;

- морфологические изменения;

- уменьшение альвеолярно-капиллярной поверхности;

- уменьшение диаметра мелких воздухоносных путей;

- нарушения в составе легочного матрикса;

- увеличение количества слизистых и уменьшение реснитчатых клеток;

- снижение активности альвеолярных макрофагов и нейтрофилов;

- повышенная микробная колонизация респираторных слизистых (Haemophilus influenzae, метицилинрезистентный Staphylococcus aureus).

По мере старения организма может изменяться реакция легочной ткани на воздействие провоспалительных и фиброгенных факторов, в связи с чем сенильное легкое оказывается более чувствительным к повреждающему эффекту различных поллютантов, табачного дыма, фиброгенных веществ, которым пожилой больной подвергается на протяжении всей жизни.

Воздействие табачного дыма вызывает хронический воспалительный процесс как в бронхоальвеолярных, так и в интерстициальных структурах легкого. Различаются также интерстициальные изменения, вызванные курением (десквамативная интерстициальная пневмония, ИЗЛ, ассоциированная с бронхиолитом, легочный гистиоцитоз из клеток Лангерганса). Считается, что с учетом распространения курения среди населения табачный дым, наряду с другими агентами, является фактором риска развития не только ХОБЛ, но и ИЛФ [16-18]. 
При использовании КТ высокого разрешения (КТВР) выделяются в особый синдром случаи комбинации ИЛФ и эмфиземы легких, имеющие неблагоприятный прогноз в связи с частым развитием легочной гипертонии [19].

Сенильное легкое оказывается более чувствительным к воздействию различных лекарственных препаратов, обладающих фиброгенными свойствами, что было показано в эксперименте. Так, у мышей с искусственно ускоренным старением выявляется избыточный провоспалительный эффект блеомицина - препарата, вызывающего легочный фиброз, причем большая степень фиброза коррелирует с выраженностью мобилизации костномозговых фибробластов и высоким уровнем профиброгенного цитокина - трансформирующего фактора роста (TGF)-1 [20]. В результате анализа экспериментальных данных установлено, что легочные фибробласты старых мышей становятся более чувствительными к повреждению ДНК под влиянием оксидативного стресса [21], а вследствие применения антиоксидантов уменьшается выраженность повреждения [22]. Возможно, что при возрастных нарушениях клеточного гомеостаза может повышаться чувствительность к оксидативному стрессу и развитию легочного фиброза [23].

Определенную роль в развитии лекарственных и других форм ИЗЛ могут играть генетические факторы [24]. В настоящее время известны различные нарушения на генном уровне (специфические генные мутации и полиморфизмы генов), ассоциированные с легочным фиброзом [25, 26]. Особая роль придается 2 факторам, выступающим в качестве медиаторов развития легочного фиброза - эндотелину- 1 и фактору тканевого роста- $\beta$, которые могут обладать синергичным действием [27, 28]. О генетической предрасположенности к развитию легочного фиброза могут свидетельствовать такие факты, как различная реакция легочной ткани инбредных мышей на воздействие фиброгенных факторов, а также вариации в частоте развития пневмокониозов у лиц, подвергавшихся в силу своей профессии длительной экспозиции фиброгенных пылевых веществ [29]. С позиций понимания механизмов возрастной предрасположенности к развитию легочного фиброза представляет интерес выявленное возрастзависимое снижение теломеразной активности в соматических клетках человека [30], что ослабляет ингибиторный эффект теломеразы в процессе дифференцировки фибробластов в миофибробласты [31]. Обсуждается потенциальный вклад возрастного укорочения теломер в нарушение регенераторной способности альвеолярного эпителия [32]. Аномально укороченные теломеры были выявлены в альвеолярном эпителии у пациентов с ИЛФ [33], а генные мутации фермента, ответственного за поддержание длины теломер (теломеразы) ассоциировались с наследственной формой ИЛФ [34].

С учетом возрастающей частоты ИЛФ у пожилых лиц мутация генов теломеразной активности может приобретать большое значение в предрасположен- ности их к развитию заболевания. Показано, что в стареющих фибробластах нарушена экспрессия рецепторов ингибитора активации фибриногена-1, который ассоциируется с развитием фиброза [35]. В результате анализа показателей у 100 больных ИЛФ и 263 лиц контрольной группы, сопоставимой по полу, возрасту, месту проживания (случай-контроль) установлено, что семейные случаи заболевания являются важным фактором риска развития ИЛФ (отношение шансов - ОШ = 6, 1 ; 95\%-ный доверительный интервал - ДИ $-2,3-15,9 ; p<0,0001)$ наряду с наличием гастроэзофагеальной рефлюксной болезни (ГЭРБ) (ОШ = 2,9, ДИ - 1,3-6,6; $p=0,007)$, курения в прошлом (ОШ $=2,5 ;$ ДИ $-1,4-4,6 ; p=0,003)$, бытовых и профессиональных воздействий пыли, газов, химических веществ (ОШ $=2,8$; ДИ $-1,5-5,5$; $p=0,002)$ [36]. Имеются данные о патогенетическом значении ГЭРБ, микроаспираций, столь частых в пожилом возрасте и клинически не манифестирующихся, в развитии ИЛФ у пожилых [37].

Лекарственные легочные фиброзы возникают при длительном применении цитостатических (миелосан, циклофосфамид, блеомицин, метотрексат) медикаментозных средств, фурадонина и др. Так, при систематическом лечении гипертонии ганглиоблокаторами пневмофиброз может развиться спустя 10-12 мес. после назначения препарата, фурадонина - при приеме медикамента от 6 мес. до 6 лет.

\section{Диагностика ИЛФ у пожилых}

Диагностика ИЛФ у больных пожилого и старческого возраста представляет определенные трудности, обусловленные, с одной стороны, отсутствием специфической симптоматики, а с другой - наличием различных коморбидных состояний, которые маскируют основное заболевание, конкурируют по своим проявлениям с легочной симптоматикой и нередко выступают в клинической картине на первый план.

Наличие ИЛФ у пожилого больного следует заподозрить в случаях нарастающей одышки и непродуктивного кашля при исключении другой патологии (сердечная недостаточность, ХОБЛ, опухолевый процесс в легких и т. п.), которая нередко может маскировать ИЛФ у данной категории пациентов. При этом следует учитывать наличие возможных этиологических факторов (воздействие токсических веществ, прием различных медикаментов, системная патология и т. п.). Характерна аускультативная симптоматика, в частности наличие двусторонних трескучих хрипов, которые необходимо дифференцировать с застойными хрипами у больных сердечной недостаточностью. Возрастные морфологические изменения легочной ткани в виде повышенной склонности к коллапсу малых дыхательных путей могут быть причиной трескучих хрипов, трактовка которых у лиц старческого возраста не всегда однозначна [38]. Нередко наблюдается утолщение концевых фаланг пальцев рук и ног (гипертрофическая остеоартропатия). При исследовании функции внешнего 
дыхания обычно регистрируются рестриктивные нарушения и снижение диффузионной способности легких. По мере прогрессирования заболевания выявляется артериальная гипоксемия и снижение показателей сатурации кислорода, которые могут снижаться у пожилых пациентов вследствие возрастных инволюционных изменений легочной функции и не всегда свидетельствуют о наличии истинной легочной патологии [39]. Данное обстоятельство необходимо учитывать при трактовке этих показателей в процессе диагностического поиска у пожилых в случаях подозрения на ИЛФ.

Лучевая диагностика является основным параклиническим методом при подозрении на ИЛФ, причем при обычной рентгенограмме в условиях легочной и сердечно-сосудистой коморбидности у пожилых не всегда возможно не только диагностировать, но и заподозрить заболевание.

"Золотым стандартом" диагностики ИЛФ в клинической практике остается КТВР. Лучевыми признаками ИЛФ принято считать субплевральные, обычно симметричные, преимущественно в базальных отделах, реже диффузные, сетчато-узловые изменения, непостоянные междолевые линейные тени, тракционные бронхоэктазы, легочные кисты по типу медовых сот. Изменения по типу матового стекла нехарактерны или умеренно выражены [40, 41].

Сложности лучевой диагностики ИЛФ у пожилых обусловлены тем, что с возрастом рентгенологическая картина легких претерпевает изменения, не связанные с какой-либо определенной патологией. В результате исследований у лиц в возрасте 75 лет и старше при отсутствии функциональных легочных нарушений были выявлены КТ-признаки, отличающиеся от таковых у молодых лиц и включающие базальные, преимущественно двусторонние субплевральные сетчатые участки, а также кистозные изменения [42]. Выявленные у пожилых скиалогические изменения в легких могут быть одним из проявлений сенильного легкого, не позволяющих интерпретировать их как патологические при отсутствии клинической симптоматики и функциональных легочных нарушений. В ряде случаев подобные субклинические изменения легочного интерстиция, характерные для пожилых и курящих лиц, выявляются при случайном рентгенологическом обследовании и могут служить причиной гипердиагностики ИЛФ.

С целью оптимизации диагностики ИЛФ у пожилых разработана специальная оценивающая шкала, включающая сумму возраста больных и КТ-признаков в их количественном (балльном) выражении [43]. На основании ретроспективного анализа пациентов $(n=135)$ с морфологически верифицированным ИЛФ было показано, что пожилой и старческий возраст в сочетании с количественным интерстициальным показателем по результатам КТВР позволяют с высокой достоверностью предсказать вероятность ИЛФ по отношению к другим формам идиопатической интерстициальной пневмонии. Балльная система имеет 100\%-ную предсказательную ценность для ИЛФ у больных в возрасте 55 лет и старше при количественно невыраженном фиброзе по данным КТВР (средние показатели на КТВР 0,8-1,0). Подчеркивается практическая ценность балльной оценки изменений на КТВР при диагностике ИЛФ у пожилых, поскольку методы инвазивной диагностики (трансбронхиальная и трансторакальная биопсии) сопряжены с риском развития осложнений и ухудшения состояния пациентов данной возрастной категории (декомпенсация сопутствующей патологии).

Несмотря на привлекательность предлагаемой методики, в диагностике ИЛФ использование результатов данного исследования имеет определенные ограничения, на что указывалось в последующих дискуссиях [44]: во-первых, результаты применимы только у пациентов с подозрением на ИЛФ, у которых не отмечалось клинических признаков, а при КТВР не выявлено изменений по типу медовых сот; во-вторых, распространение ИЛФ в этой группе было довольно высоко (72 \%), и истинное распространение заболевания в общей популяции может не отражаться; в-третьих, положительная прогнозируемая ценность предлагаемой модели снижается, если распространенность заболевания низкая. Несмотря на эти ограничения, исследование может изменить подходы к диагностике ИЛФ в будущем. В диагностике ИЛФ могут оказаться перспективными разрабатываемые новые генетические методы дифференциальной диагностики ИЛФ от некоторых других форм ИЗЛ [45].

Основные трудности диагностики ИЛФ у лиц пожилого и старческого возраста заключаются в том, что заболевание нередко развивается на фоне имеющихся коморбидных состояний (ХОБЛ, бронхиальная астма, сердечная недостаточность). По мере развития, течения и прогрессирования заболевания наступает декомпенсация сопутствующей патологии, выступающей на первый план в клинической картине. У больных сопутствующей ИБС на фоне гипоксии в результате развивающейся дыхательной недостаточности могут усугубляться симптомы стенокардии, которая служит поводом для госпитализации. В подобных случаях распознавание ИЛФ представляет известные трудности, а диагноз ставится лишь при патологоанатомическом исследовании. Нередко легочная симптоматика у пожилых больных трактуется как проявление обострения ХОБЛ или пневмонии, по поводу которых назначается антибактериальная терапия. Однако ответ на лечение оказывается недостаточным или вообще отсутствует, что неизбежно влечет за собой эскалацию антибактериального лечения и необходимость исключения опухолевого процесса в легких.

Ключом к диагностике ИЛФ у пожилых при наличии респираторной симптоматики и рентгенологических изменений в легких могут быть следующие признаки:

- отсутствие эффекта от антибактериальной терапии (при подозрении на пневмонию);

- наличие внелегочных проявлений (лихорадка, устойчивая к антибиотикам, суставно-мышечный синдром, синдром Рейно); 
- рестриктивные нарушения по данным исследования функции внешнего дыхания;

- длительный прием некоторых медикаментов (метотрексат, амодарон, нитрофураны, психотропные препараты и т. п.);

- отсутствие очевидной патологии, которой объясняется клиническая симптоматика.

При помощи исследования бронхоальвеолярной жидкости (БАЛЖ) и трансбронхиальной биопсии возможно верифицировать соответствующую форму ИЗЛ и сузить круг диагностического поиска, исключив некоторые сходные заболевания. С внедрением в клиническую практику КТВР проведения биопсии легких можно в некоторых случаях избежать. По этой же причине отмечается очевидная тенденция к снижению частоты использования бронхоскопии с исследованием БАЛЖ. Бронхоскопия была включена в диагностические рекомендации по соглашению $\approx 2000$ экспертов [6]. В настоящее время имеется тенденция к значительному сужению показаний для проведения бронхоскопии с трансбронхиальной биопсией и торакоскопической биопсии легкого с диагностической целью для подтверждения диагноза ИЛФ [46]. Это связано с высоким риском осложнений, вплоть до летальных исходов при проведении легочной биопсии у пожилых пациентов, особенно с тяжелой дыхательной недостаточностью и при наличии полиморбидности [47, 48]. Среди больных $(n=194)$, подвергнутых видеоторакоскопической биопсии легких с целью верификации формы ИЗЛ, летальность составила 6,7 \%, причем основными факторами риска смерти были необходимость ИВЛ до операции (100,0\% vs 4,8 \% больных со спонтанным дыханием). Средний возраст умерших после операции был старше 64,9 и 57,5 года соответственно [49].

Показаниями к биопсии легкого могут быть атипичные клинические проявления заболевания и отсутствие характерных скиалогических признаков по результатам КТВР, особенно у больных с недавно возникшей симптоматикой. В подобных случаях диагноз ИЗЛ может быть верифицирован лишь по данным гистологического исследования легочного биоптата [8]. С использованием биопсии легких удельный вес неклассифицируемых ИЗЛ сузился до $25 \%$, в то время как еще 10 лет тому назад ИЗЛ неизвестной этиологии составляли > $50 \%$ [29].

Морфологической основой ИЛФ является сочетание следующих признаков:

- мозаичный фиброз;

- фибробластические фокусы;

- "сотовые" изменения и / или формирование рубцовых изменений.

Основным диагностическим критерием ИЛФ с позиций морфолога является совокупность признаков обычной интерстициальной пневмонии (ОИП) морфологического синонима ИЛФ. Эти признаки включают наличие гетерогенных изменений в легких вследствие развития фиброзных, "сотовых" изменений, интерстициального воспаления наряду с наличием неизмененных участков легочной ткани. В зависимости от стадии заболевания выраженность описанных изменений может изменяться. При классической ОИП фиброзные изменения обычно превалируют над воспалительной инфильтрацией и характеризуются избыточным развитием и отложением коллагена. Воспалительная инфильтрация обычно выражена не резко и формируется мелкими лимфоцитами, возможно, с примесью плазматических клеток, иногда скоплением В-лимфоцитов. Фибробластические фокусы представляют собой мелкие очаги острого повреждения с наличием фибробластов и миофибробластов, пролиферацией альвеолоцитов 2-го типа и нежно окрашиваемого межклеточного вещества. Кистозные образования по типу медовых сот обнаруживаются в большинстве легочных биоптатов в виде расширенных воздушных пространств, выстланных бронхиальным эпителием и заполненных слизью и клетками воспаления среди очагов фиброза. Типичным гистологическим признаком ОИП считаются участки фиброза, не связанные с "сотами", причем в очагах фиброза и в стенках "сот" часто можно видеть гиперплазию гладких мышц, иногда весьма выраженную. Возможна плоскоклеточная метаплазия бронхиолярного эпителия, а также эпителия, выстилающего аденоматозные "сотовые" структуры [4, 50].

В Рекомендациях (2011) приведены диагностические критерии ИЛФ [51]:

- отсутствие возможных причин ИЛФ (экзогенные факторы, в т. ч. профессиональные, системные заболевания, прием лекарственных препаратов);

- наличие признаков ОИП на КТВР (достаточный признак для лиц, у которых не выполнялась биопсия легких);

- наличие признаков ОИП при КТВР и характерных морфологических черт в образцах ткани легкого, полученных при хирургической биопсии.

В данной версии подчеркивается, что ИЛФ не является только клиническим диагнозом и должен быть подтвержден при проведении КТ, а по возможности хирургической (не трансбронхиальной) биопсией легкого. Важным является конструктивное взаимодействие разных специалистов (клиницист, рентгенолог, морфолог) в процессе диагностического поиска у больных с подозрением на ИЗЛ, что способствует улучшению диагностики заболевания [52, 53].

На рисунке представлен диагностический алгоритм при подозрении на ИЗЛ и место различных методов исследования в процессе диагностического поиска.

\section{Коморбидность и течение ИЛФ у пожилых больных}

Коморбидность, являющаяся характерным клиническим признаком у лиц пожилого и старческого возраста, считается одним из прогностических факторов снижения продолжительности жизни больных ИЛФ после трансплантации легких. К тому же при коморбидности и приеме лекарственных препаратов, назначаемых по поводу сопутствующих заболеваний, может изменяться клиническая картина, при этом затрудняются диагностика и лечение заболевания. 
Подозрение на ИЗЛ

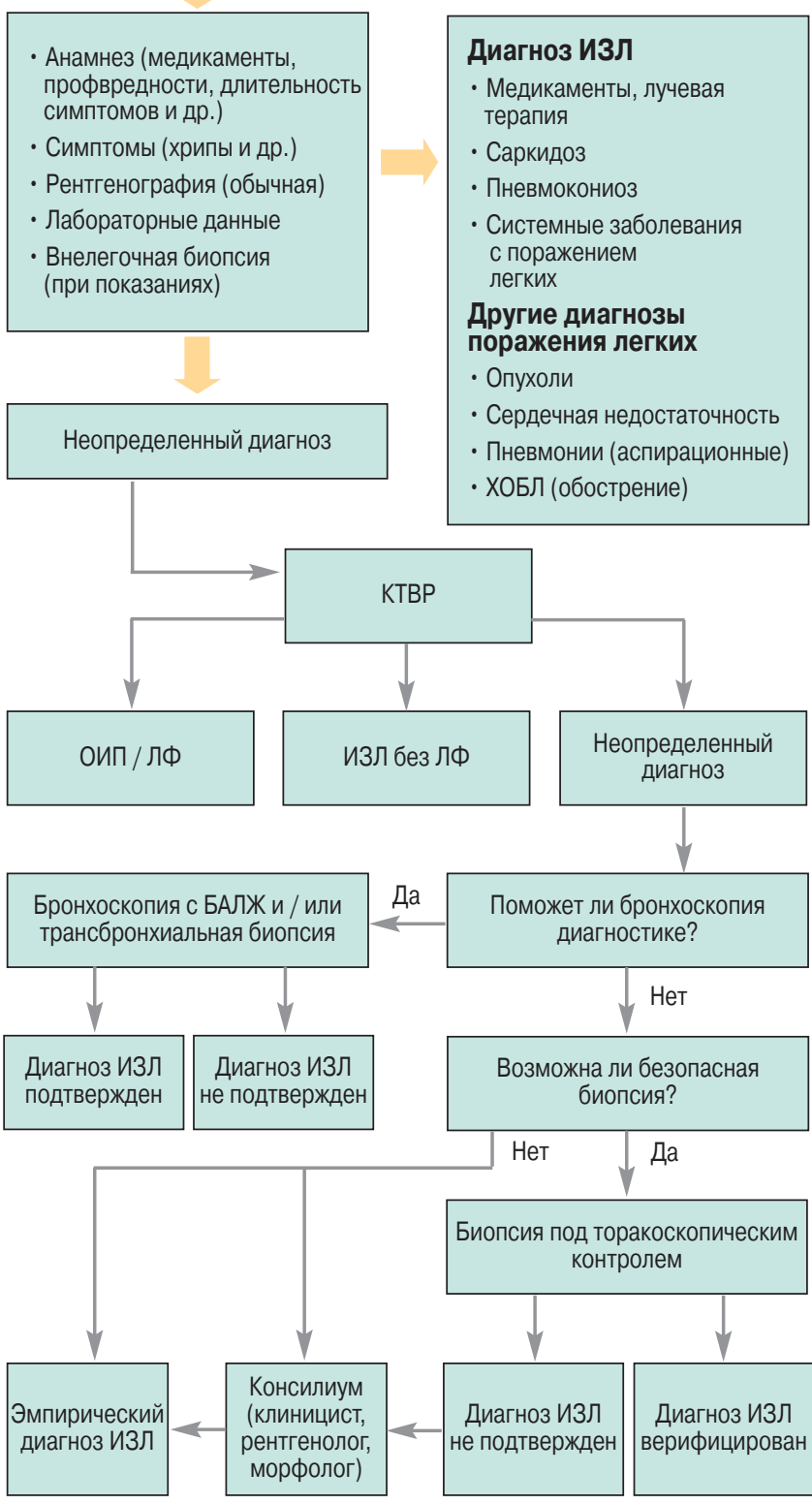

Рисунок. Диагностический алгоритм при подозрении на ИзЛ у пожилых лиц [29]

Наиболее часто пожилые больные ИЛФ коморбидны к ИБС, обструктивному апноэ во сне, сахарному диабету, ГЭРБ, потере мышечной массы, стероидному остеопорозу, а после 60 лет - к ГЭРБ [54-60], при которой возрастает риск госпитализации, главным образом по поводу ухудшения течения легочного заболевания, возможно, на фоне неконтролируемого гастроэзофагального рефлюкса и персистирующих микроаспираций. Показано, что при достаточном контроле ГЭРБ улучшается течение ИЛФ, что в известной мере позволяет предполагать роль ГЭРБ (микроаспирации) в повреждении альвеолярного эпителия и прогрессировании легочного фиброза [61, 62].

Клиническое течение, прогрессирование, наличие и характер осложнений, развитие дыхательной недостаточности, ответ на лечение ИЛФ у пожилых весьма вариабельны. Если у одних больных заболевание протекает относительно стабильно, без выраженной дыхательной недостаточности, то у других наблюдается прогрессирование с быстро ухудшающейся функцией легких, нарастанием дыхательной недостаточности и летальным исходом [63, 64].

Нередко на фоне относительно стабильного течения возникает декомпенсация респираторного статуса, служащая поводом для госпитализации, в т. ч. в отделение интенсивной терапии. Подобные эпизоды быстрого ухудшения состояния обозначаются как обострения ИЛФ [65]. Подобные обострения развиваются у 5-15\% больных ИЛФ и их причинами могут быть скрытые, неманифестирующие инфекции, ГЭРБ, легочные эмболии, спонтанный пневмоторакс, декомпенсация сопутствующей патологии (сердечная недостаточность, нарушения ритма сердца, ГЭРБ), побочные действия лекарственной терапии [66]. Однако в большинстве случаев причины ухудшения состояния больных ИЛФ остаются нераскрытыми, несмотря на тщательное обследование. Не всегда представляется возможным отличить прогрессирование основного заболевания от декомпенсации коморбидных состояний (сердечная недостаточность, ХОБЛ и др.) или осложнений лекарственной терапии (ятрогенных). Течение ИЛФ может определять фенотип заболевания. Предлагается выделить 3 фенотипа ИЛФ:

- легочный фиброз с эмфиземой;

- ИЛФ с легочной гипертензией;

- быстро прогрессирующий ИЛФ [67].

Наиболее частой причиной смерти пожилых больных ИЛФ является дыхательная недостаточность $(38,7$ \%). Другие причины включают сердечную недостаточность $(14,4 \%)$, бронхогенный рак $(10,4 \%)$, ИБС (9,5\%), инфекция $(6,5 \%)$, тромбоэмболия легочной артерии $(3,4 \%)$ [68]. Одной из причин смерти пожилых больных ИЛФ с сопутствующей ИБС является инфаркт миокарда, который не всегда диагностируется прижизненно. Так, имеется клиническое наблюдение больной ИЗЛ 78 лет, длительно леченной глюкокортикостероидами и скончавшейся при нарастающих признаках дыхательной недостаточности. При патологоанатомическом исследовании был обнаружен острый инфаркт миокарда, не диагностированный при жизни больной. Вклад дыхательной недостаточности на фоне ИЗЛ в развитие инфаркта миокарда у больных ИБС не всегда оказывается доказанным, но представляется вполне реальным.

Летальность и ее риск у пациентов с ИЛФ во многом обусловлены наличием легочной гипертензии, частота которой возрастает после 60 лет [69-71], при которой ухудшается прогноз и уменьшается продолжительность жизни [72]. Худший прогноз наблюдается у больных ИЛФ в сочетании с эмфиземой легких и, вероятно, с более частой и выраженной легочной гипертензией [73, 74].

При оценке состояния пожилого больного с любой патологией, в том числе и с ИЛФ, основным 
Основные препараты и механизмы их действия при лечении больных ИЛФ [29]

\begin{tabular}{|c|c|c|}
\hline Препарат & $\begin{array}{c}\text { Патогенетические } \\
\text { мишени }\end{array}$ & Механизмы действия \\
\hline Пирфенидон & TGF- $\beta$ & Снижение синтеза коллагена, стимулированного TGF- $\beta$, и накопления внеклеточного матрикса \\
\hline \multicolumn{3}{|l|}{ Антитела к TGF- $\beta$} \\
\hline Бозентан & Эндотелин-1 & $\begin{array}{l}\text { Угнетение продукции TGF- } \beta \text { и стимуляции фибробластов / миофибробластов путем } \\
\text { антагонизма к эндотелину-1 }\end{array}$ \\
\hline Этанерсепт & TNF- $\alpha$ & Угнетение митогенных эффектов TNF- $\alpha$ на фибробласты и синтез коллагена \\
\hline $\mathrm{N}$-ацетилцистеин & $\begin{array}{l}\text { Баланс оксиданты- } \\
\text { антиоксиданты }\end{array}$ & $\begin{array}{l}\text { Восполнение легочных запасов глютатиона, препятствующего повреждающему действию } \\
\text { кислородных радикалов (стимулирующему эффекту на миофибробласты) }\end{array}$ \\
\hline Иматиниб мезилат & Протеинкиназы & Угнетение пролиферации фибробластов, опосредованной протеинкиназой \\
\hline Антитела к CTGF & CTGF & Угнетение CTGF-опосредованной стимуляции фибробластов \\
\hline \multicolumn{3}{|l|}{ Кортикостероиды } \\
\hline Азатиоприн & Воспаление & Угнетение воспалительного процесса, отвечающего на иммуносупрессивную терапию \\
\hline \multicolumn{3}{|l|}{ Циклофосфамид } \\
\hline Силденафил & Вазоконстрикция & Снижение легочной гипертензии \\
\hline Ингаляции эпопрос & & \\
\hline
\end{tabular}

критерием состояния является не столько характер самой патологии, выраженность клинических и лабораторных признаков, сколько функциональный статус больного [75]. Среди больных ИЛФ - кандидатов для легочной трансплантации тест с 6-минутной ходьбой является более информативным в предсказании продолжительности жизни, чем показатель легочных функций [76]. Неблагоприятными факторами риска повышенной летальности у пожилых больных ИЛФ являются такие коморбидности, как депрессии и когнитивные нарушения [77].

Показано, что одышка в большей степени ассоциируется с депрессией и тревогой, чем с функциональным состоянием легких. В то же время при лечении, направленном на купирование депрессии и психологическую поддержку больных ИЛФ, существенно уменьшается одышка и увеличивается пройденное расстояние при проведении 6-минутного шагового теста [78, 79]. Средняя продолжительность жизни пациентов с ИЛФ короче, чем при других формах ИИП, например интерстициальной неспецифической пневмонии, и колеблется, по различным данным, от 2 до 5 лет [80].

\section{Ведение пожилых больных ИЛФ}

Полученные данные о патогенетических механизмах развития ИЛФ позволяют в настоящее время обосновать и позиционировать применение фармакологических препаратов различных классов в расчете их воздействия на различные патогенетические механизмы заболевания. Терапевтические акценты делаются преимущественно на угнетение процесса фиброза легких. В таблице приводятся основные подходы к медикаментозной терапии пациентов с ИЛФ.

Неотъемлемым и существенным компонентом в ведении пожилых больных ИЛФ является коррекция сопутствующей патологии, в частности сердечной недостаточности, легочной гипертензии, нарушений ритма сердца, дыхательных нарушений во сне, ГЭРБ, остеопороза, коррекции массы тела, контроль медикаментозной терапии. Менее актуальной у данной категории пациентов следует считать трансплантацию легких [29].

\section{Литература / References}

1. King Jr T.E., Collard H., Richeldi L. Preface. Clin. Chest Med. 2012; 33 (1): 23.

2. Илькович М.М. Диссеминированные заболевания легких. М.: ГЭОТАР; 2011. / Il'kovich M.M., ed. Disseminated Lung Diseases. [Disseminirovannye zabolevaniya legkikh]. Moscow: GEOTAR; 2011 (in Russian).

3. Капустина В.А, Овчаренко С.И. Эволюция классификации интерстициальных заболеваний легких. Что нового дает пересмотр классификации 2012 года? Consilium Medicum. 2013;15 (3): 33-35. / Kapustina V.A., Ovcharenko S.I. Evolving classification of interstitial lung disease. What is new in the revised classification of 2012? Consilium Medicum. 2013; 15 (3): 33-35 (in Russian).

4. Черняев А.Л., Самсонова М.В. Идиопатическая интерстициальная пневмония - классификация и патологическая анатомия. Атмосфера. Пульмонология и аллергология. 2013; 2: 51-56. / Chernyaev A.L., Samsonova $M . V$. Idiopathic interstitial pneumonia: classification and pathologic anatomy. Atmosfera. Pul'monologiya i allergologiya. 2013; 2: 51-56 (in Russian).

5. American Thoracic Society / European Respiratory Society. International multidisciplinary consensus classification of the idiopathic interstitial pneumonias. Am. J. Respir. Crit. Care Med. 2002; 165: 277.

6. Katzenstein A.L., Mukhopadhyay S., Myers J. Diagnosis of usual interstitial pneumonia and distinction from other fibrosing interstitial lung diseases. Hum. Pathol. 2008; 39: 1275 .

7. Fernandez Perez E.R., Daniels C.E., Schroeder D.R. et al. Incidence, prevalence, and clinical course of idiopathic pulmonary fibrosis: a population-based study. Chest. 2010; 137: 129-137.

8. American Thoracic Society. Idiopathic pulmonary fibrosis: diagnosis and treatment. International consensus statement. American Thoracic Society (ATS), and the European Respiratory Society (ERS). Am. J. Respir. Crit. Care Med. 2000; 16: 1646-1664. 
9. Raghu G., Weycker D., Edelsberg J. et al. Incidence and prevalence of idiopathic pulmonary fibrosis. Am. J. Respir. Crit. Care Med. 2006; 174: 810-816.

10. Coultas D.B., Zumwalt R.E., Black W.C., Sobonya R.E. The epidemiology of interstitial lung diseases. Am. J.Respir. Crit. Care Med 1994; 150: 967-972.

11. Gribbin J., Hubbard R.B., Le Jeune I. et al. Incidence and mortality of idiopathic pulmonary fibrosis and sarcoidosis in the UK. Thorax. 2006; 61: 980-985.

12. Olson A.L., Swigris J.J., Lezotte D.C. et al. Mortality from pulmonary fibrosis increased in the United States from 1992 to 2003. Am. J. Respir. Crit. Care Med. 2007; 176: 277-284.

13. Castriotta R.J., Eldadah B.A., Foster M.W. et al. Workshop on idiopathic pulmonary fibrosis in older adults. Chest. 2010; 138 (3): 693-703.

14. Dyer C.A., Stockley R.A. The aging lung. Rev. Clin. Gerontol. 2006; 16: 99-111.

15. Dyer $C$. The interaction of ageing and lung disease. West. Engl. Med. J. 2011; 110 (1): 3.

16. Garantziotis S., Schwartz D.A. Host-environment interactions in pulmonary fibrosis. Semin. Respir. Crit. Care Med. 2006; 27: 574-580.

17. Taskar V.S., Coultas D.B. Is idiopathic pulmonary fibrosis an environmental disease? Proc. Am. Thorac. Soc. 2006; 3: 293-298.

18. Vassallo R., Ryu J.H. Smoking-related interstitial lung diseases. Clin. Chest Med. 2012; 33: 165-178.

19. Cerri S., Spagnolo P., Luppi F. et al. Smoking-related interstitial lung disease. In: Cordier J-F. (ed.). Orphan Lung Diseases. Eur. Respir. Soc. Monograph. 2011; 54: 282-300.

20. Хи J., Gonzalez E.T., Iyer S.S. et al. Use of senescenceaccelerated mouse model in bleomycin-iniduced lung injury suggests that bone marrow-derived cells can alter the outcome of lung injury in aged mice. J. Gerontol. 2009; 64A: 731-739.

21. Lopez-Diazguerrero N.E., Luna-Lopez A., Gutierrez-Ruiz M.C. et al. Susceptibility of DNA to oxidative stressors in young and aging mice. Life Sci. 2005; 77: 2840-2854.

22. Zhang H.J., Doctrow S.R., Oberley L.W., Kregel K.C. Chronic antioxidant enzyme mimetic treatment differentially modulates hyperthermia-induced liver HSP70 expression with aging. J. Appl. Physiol. 2006; 100: 1385-1391.

23. Cuervo A.M. Autophagy and aging: keeping that old broom working. Trends Genet. 2008; 24: 604-612.

24. Delaunois M.S. Mechanisms in pulmonary toxicology. Clin. Chest Med. 2004; 25: 1-14.

25. Lawson W.E., Loyd J.E. The genetic approach in pulmonary fibrosis: can it provide clues to this complex disease? Proc. Am. Thorac. Soc. 2006; 3: 345-349.

26. Garcia C.K., Raghu G. Inherited interstitial Lung Disease. Clin. Chest Med. 2004; 25: 421-433.

27. Hocher B., Schwarz A., Fagan K.A. et al. Pulmonary fibrosis and chronic lung inflammation in ET-1 transgenic mice. Am. J. Respir. Cell Mol. Biol. 2000; 23: 19-26.

28. Kulasekaran P., Scavone C.A., Rogers D.S. et al. Endothelin-1 and transforming growth factor-1 independently induce fibroblast resistance to apoptosis via AKT activation. Am. J. Respir. Cell Mol. Biol. 2009; 41: 484.

29. Meyer K.C. Interstitial lung disease in the elderly: pathogenesis, diagnosis and management. Sarcoidos. Vasculit. Diffuse Lung Dis. 2011; 28: 3-17.

30. Collins K., Mitchell J.R. Telomerase in the human organism. Oncogene. 2002; 21: 564-579.

31. Liu T., Hu B., Chung M.J. et al. Telomerase regulation of myofibroblast differentiation. Am. J. Respir. Cell Mol. Biol. 2006; 34: 625-633.
32. Thannickal V.J., Loyd J.E. Idiopathic pulmonary fibrosis: a disorder of lung regeneration? Am. J. Respir. Crit. Care Med. 2008; 178: 663-665.

33. Alder J.K., Chen J.J., Lancaster L. et al. Short telomeres are a risk factor for idiopathic pulmonary fibrosis. Proc. Natl Acad. Sci. USA. 2008; 105: 13051-13056.

34. Armanios M.Y., Chen J.J., Cogan J.D. et al. Telomerase mutations in families with idiopathic pulmonary fibrosis. N. Engl. J. Med. 2007; 356: 1317-1326.

35. Мu X.C., Staiano-Coico L., Higgine P.J. Increased transcription and modified growth state-dependent expression of the plasminogen activator inhibitor type-1 gene characterize the senescent phenotype in human diploid fibroblasts. J. Cell. Physiol. 1998; 174: 90-98.

36. Garcia-Sancho C., Buendia-Roldan I., Fernandez-Plata M.R. et al. Familial pulmonary fibrosis is the strongest risk factor for idiopathic pulmonary fibrosis. Respir. Med. 2011; 105: 1902-1907.

37. Meyer K.C. Management of interstitial lung disease in elderly patients. Curr. Opin. Pulm. Med. 2012; 18 (5): 483-492.

38. Griffith K.A., Sherrill D.L., Siegel E.M. et al. Predictors of loss of lung function in the elderly: the Cardiovascular Health Study. Am. J. Respir. Crit. Care Med. 2001; 1631: 61-68.

39. Roversi P., Pistolesi M., Fabbri L.M. Il mito dell' enfisema senile. In: $49^{\circ}$ Congresso Nazionale la geriatria nel servizio sanitario nazionale. Firenze, 3/7 november 2004. Firenze; 2004.

40. Hunninghake G., Lynch D., Galvin J. et al. Radiologic findings are strongly associated with a pathologic diagnosis of usual interstitial pneumonia. Chest. 2003; 124: 1215-1223.

41. Lynch D.A., Travis W.D., Muller N.L. et al. Idiopathic interstitial pneumonias: CT features. Radiology. 2005; 236: 10-21.

42. Copley S.J., Wells A.U., Hawtin K.E. et al. Lung morphology in the elderly: comparative CT study of subjects over 75 years old versus those under 55 years old. Radiology. 2009; 251 (2): 566-573.

43. Fell C.D., Martinez F.J., Liu L.X. et al. Clinical predictors of a diagnosis of idiopathic pulmonary fibrosis. Am. J. Respir. Crit. Care Med. 2010; 181: 832-837.

44. Collard H.R. The age of idiopathic pulmonary fibrosis. Am. J. Respir. Crit. Care Med. 2010; 181 (8): 771-772.

45. Selman M., Pardo A., Barrera L. et al. Gene expression profiles distinguish idiopathic pulmonary fibrosis from hypersensitivity pneumonitis. Am. J. Respir. Crit. Care Med. 2006; 173: 188-198.

46. Schmidt S.L., Sundaram B., Flaherty K.R. Diagnosing fibrotic lung disease: when is high-resolution computed tomography sufficient to make a diagnosis of idiopathic pulmonary fibrosis? Respirology. 2009; 14: 934-939.

47. Kreider M.E., Hansen-Flaschen J., Ahmad N.N. et al. Coomplications of video-assisted thoracoscopic lung biopsy in patients with interstitial lung disease. Ann. Thorac Surg. 2007; 83: 1140-1145.

48. Lettieri C.J., Veerappan G.R., Helman D.L. et al. Outcomes and safety of surgical lung biopsy for interstitial lung disease. Chest. 2005; 127: 1600-1605.

49. Kayatta M., Hammel J., Staton G. et al. Surgical biopsy for diagnosis of interstitial lung disease is superior to high resolution CT imaging. Chest. 2012; 142: 4.

50. Katzenstein A.L., Zisman D.A., Litzky L.A. et al. Usual interstitial pneumonia: histologic study of biopsy and explant specimens. Am. J. Surg. Pathol. 2002; 26: 1567-1577.

51. Radhu G., Collard H., Egan J. et al. An official ATS / ERS / JRS / ALAT statement: Idiopathic pulmonary fibrosis: Evidence-based guidelines for diagnosis and treatment. Am. J. Respir. Crit. Care Med. 2011; 183: 788-824. 
52. Фомин В.В., Попова Е.Н., Лебедева М.В., Шовская Т.Н. Идиопатический легочный фиброз: близки ли мы к общепринятым стандартам диагностики и лечения? Фарматека. 2012; 5: 10-14. / Fomin V.V., Popova E.N., Lebedeva M.V., Shovskaya T.N. Idiopathic pulmonary fibrosis: did we approach to worldwide standards of diagnosis and treatment? Farmateka. 2012; 5: 10-14 (in Russian).

53. Flaherty K.R., King T.E. Jr, Raghu G. et al. Idiopathic interstitial pneumonia: what is the effect of a multidisciplinary approach to diagnosis? Am. J. Respir. Crit. Care Med. 2004; 170: 904-910.

54. Enomoto T., Usuki J., Azuma A. et al. Diabetes mellitus may increase risk for idiopathic pulmonary fibrosis. Chest. 2003; 123 (6): 2007-2011.

55. Gribbin J., Hubbard R., Smith C. Role of diabetes mellitus and gastro-oesophageal reflux in the aetiology of idiopathic pulmonary fibrosis. Respir. Med. 2009; 103 (6): 927-931.

56. Garcia-Sancho Figueroa M.C., Carrillo G., Perez-Padilla R. et al. Risk factors for idiopathic pulmonary fibrosis in a Mexican population. A case-control study. Respir. Med. 2009; 104 (2): 305-309.

57. Lancaster L.H., Mason W.R., Parnell J.A. et al. Obstructive sleep apnea is common in idiopathic pulmonary fibrosis. Chest. 2009; 136 (3): 772-778.

58. Zisman D.A., Kawut S.M., Lederer D.J. et al. Serum albumin concentration and waiting list mortality in idiopathic interstitial pneumonia. Chest. 2009; 135 (4): 929-935.

59. Kizer J.R., Zisman D.A., Blumenthal N.P. et al. Association between pulmonary fibrosis and coronary artery disease. Arch. Intern. Med. 2004; 164 (5): 551-556.

60. Raghu G., Freudenberger T.D., Yang S. et al. High prevalence of abnormal acid gastro-oesophageal reflux in idiopathic pulmonary fibrosis. Eur. Respir. J. 2006; 271: $136-142$.

61. Raghu G., Yang S.T., Spada C.A. et al. Sole treatment of acid gastroesophageal reflux in idiopathic pulmonary fibrosis: a case series. Chest. 2006; 129 (3): 794-800.

62. Linden P.A., Gilbert R.J., Yeap B.Y. et al. Laparoscopic fundoplication in patients with end-stage lung disease awaiting transplantation. J. Thorac. Cardiovasc. Surg. 2006; 131 (2): 438-446.

63. Martinez F.J., Safrin S., Weycker D. et al. The clinical course of patients with idiopathic pulmonary fibrosis. Ann. Intern. Med. 2005; 142: 963-967.

64. Brown K.K., Raghu G. Medical treatment for pulmonary fibrosis: current trends, concepts, and prospects. Clin. Chest Med. 2004; 25: 759-772.

65. Kim D.S. Acute exacerbation of idiopathic pulmonary fibrosis. Clin. Chest Med. 2012; 33 (1): 59-68.

66. Collard H.R., Moore B.B., Flaherty K.R. et al. Acute exacerbations of idiopathic pulmonary fibrosis. Am. J. Respir. Crit. Care Med. 2007; 176: 636-643.
67. Fell C.D. Idiopathic pulmonary fibrosis: Phenotypes and comorbidities. Clin. Chest Med. 2012; 33 (1): 51-57.

68. Panos R.J., Mortenson R.L., Nicolli S.A. et al. Clinical deterioration in patients with idiopathic pulmonary fibrosis: cause and assessment. Am. J. Med. 1990; 8: 396-404.

69. Nathan S.D., Shlobin O.A., Ahmad S. et al. Serial development of pulmonary hypertension in patients with idiopathic pulmonary fibrosis. Respiration. 2008; 76 (3): 288-294.

70. Zisman D.A., Karlamangla A.S., Ross D.J. et al. High-resolution chest CT findings do not predict the presence of pulmonary hypertension in advanced idiopathic pulmonary fibrosis. Chest. 2007; 132 (3): 773-779.

71. Lettieri C.J., Nathan S.D., Barnett S.D. et al. Prevalence and outcomes of pulmonary arterial hypertension in advanced idiopathic pulmonary fibrosis. Chest. 2006; 129 (3): $746-752$.

72. Nadrous H.F., Pellikka P.A., Krowka M.J. et al. Pulmonary hypertension in patients with idiopathic pulmonary fibrosis. Chest. 2005; 128 (4): 2393-2399.

73. Cottin V., Le Pavec J., Prevot G. et al. Pulmonary hypertension in patients with combined pulmonary fibrosis and emphysema syndrome. Eur. Respir. J. 2010; 351: 105-111.

74. Mejia M., Carrillo G., Rojas-Serrano J. et al. Idiopathic pulmonary fibrosis and emphysema: decreased survival associated with severe pulmonary arterial hypertension. Chest. 2009; 136 (1): 10-15.

75. Lee S.J., Lindquist K., Segal M.R., Covinsky K.E. Development and validation of a prognostic index for 4-year mortality in older adults. J.A.M.A. 2006; 295 (7): 801-808.

76. Lederer D.J., Arcasoy S.M., Wilt J.S. et al. Six-minute-walk distance predicts waiting list survival in idiopathic pulmonary fibrosis. Am. J. Respir. Crit. Care Med. 2006; 174 (6): 659-664.

77. Mehta K.M., Yaffe K, Langa K.M. et al. Additive effects of cognitive function and depressive symptoms on mortality in elderly community-living adults. J. Gerontol. Biol. Sci. Med. 2003; 58 (5): M461-M467.

78. Ferreira A., Garvey C., Connors G.L. et al. Pulmonary rehabilitation in interstitial lung disease: benefits and predictors of response. Chest. 2009; 135: 442-447.

79. Nishiyama O., Kondoh Y., Kimura T. et al. Effects of pulmonary rehabilitation in patients with idiopathic pulmonary fibrosis. Respirology. 2008; 13: 394-399.

80. Collard H.R., King T.E. Jr. Demystifying idiopathic interstitial pneumonia. Arch. Intern. Med. 2003; 163: 17-29.

\section{Информация об авторе}

Дворецкий Леонид Иванович - д. м. н., профессор, зав. кафедрой госпитальной терапии № 2 лечебного факультета ГБОУ ВПО "Первый МГМУ им. И.М.Сеченова" Минздрава России; тел.: (499) 248-53-05; e-mail: dvoretski@mail.ru 